\title{
Integration of country energy system models in a Pan European framework for supporting $\mathbf{E U}$ policies
}

C. Cosmi $^{1}$, M. Blesl ${ }^{2}$, A. Kanudia ${ }^{3}$, S. Kypreos ${ }^{4}$, R. Loulou ${ }^{3}$, K. Smekens ${ }^{5}$, M. Salvia ${ }^{1}$, D. Van Regemorter ${ }^{6}$ \& V. Cuomo ${ }^{1}$ ${ }^{I}$ CNR - National Research Council, IMAA - Institute of Methodologies for Environmental Analysis, Italy

${ }^{2} I E R$ - Institute of Energy Economics and the Rational Use of Energy, University of Stuttgart, Germany

${ }^{3}$ KANLO and McGill University, Montréal, Canada

${ }^{4}$ PSI - Paul Scherrer Institut, Switzerland

${ }^{5}$ ECN - Energy Research Centre of the Netherlands, Unit Policy Studies, The Netherlands

${ }^{6}$ KUL Catholic University of Leuven - Center for Economic Studies, Belgium

\begin{abstract}
This paper deals with an experience of cooperative research carried out in the context of the EU Sixth Framework Program's Integrated Project NEEDS (2004-2008), and in particular in the research stream 2a "Modelling internalisation strategies including scenario building", co-ordinated by the IMAA - CNR. The main objective of this work is to analyse scenarios with generated partial equilibrium technology rich energy models of 29 countries (EU-25 States plus Iceland, Norway, Romania, Switzerland), integrated into a Pan-European model, capable of analysing the impacts of different policies and price mechanisms, evaluating them also at a technology level both at the country level and from an EU wide perspective. All these models, characterised by a multi-period structure (base-year: 2000, last milestone year: 2050), will include the most important life-cycle emissions, materials, and costs analysed by other NEEDS research streams (LCA and ExternE). This paper describes the current status of the work carried out in the Research Stream 2a, including the basic methodological assumptions.

Keywords: national energy system models, TIMES model generator, scenario analysis.
\end{abstract}




\section{Introduction}

NEEDS, "New Energy Externalities Developments for Sustainability" [1], is a four-year Integrated Project of the $6^{\text {th }}$ Framework Programme (Priority 6.1: Sustainable Energy Systems, Sub-priority 6.1.3.2.5: Socio-economic tools and concepts for energy strategy). Started officially on September $1^{\text {st }}, 2004$, its ultimate objective is to evaluate the full costs and benefits (i.e. direct and external) of energy policies and of future energy systems, both at the level of individual countries and for the enlarged EU as a whole. In this context NEEDS refines and develops the externalities methodology already set up in the ExternE project, through an ambitious attempt to develop, implement and test an original framework of analysis to assess the long term sustainability of energy technology options and policies.

NEEDS is structured as a series of Research Stream (RS) in order to entail major advancements in the current state of knowledge in four main areas:

- $\quad$ Life Cycle Assessment (LCA) of energy technologies

- Monetary valuation of externalities associated to energy production, transport, conversion and use

- Integration of LCA and external costs information into policy formulation and scenario building

- Multi-criterion decision analysis (MCDA), to examine the robustness of the pro-posed technological solutions with respect to stakeholder preferences

The NEEDS consortium includes 66 partners (of which some 15\% are SMEs), representing 26 Countries (12 Member States from the EU-15, 9 new EU Member States, 3 Mediterranean Countries, and 2 Countries from other parts of the World). It presents a balanced mix of Universities, Research Institutions (both public and private), Industry, and NGOs. Most leading institutions active in the area of energy externalities research are represented.

The work described in this paper deals with the activities of the research stream 2a "Modelling internalisation strategies including scenario building", which is aimed at generating a partial equilibrium economic model of the EU energy system built upon the 29 country models linked by trades of energy and emissions as well as to provide a coherent and integrated scenario analysis platform. These models will extend the usual boundaries of energy system analysis in order to include in their long term development, the most important emissions, materials, and externalities used by LCA and ExternE. The methodology and the major models' features are discussed in the following sections.

\section{Methodology}

The modelling platform for the development of the country models and the PanEuropean model is The Integrated MARKAL-EFOM System (TIMES), developed by the Energy Technology Systems Analysis Programme (ETSAP [2]) of the International Energy Agency (IEA), and widely used to implement 
national and global models worldwide (e.g. [3-6]). Several NEEDS partners are also members of ETSAP and expert developers and users of the TIMES methodology. The main components of this integrated platform are:

- a set of data files that fully describes the energy system (technologies, commodities, resources and demands for energy services) in a format compatible with the associated model generator.

- the model generator (TIMES [7]), consisting of the source code written in the GAMS (General Algebraic Modeling System [8]) computer programming language. It processes the data files, generates the matrix that specifies the mathematical programming problem, and post-processes the optimization results. - a solver, consisting of a software package integrated with GAMS which solves the mathematical programming problem.

- a "shell", i.e. a user interface named the Versatile Data Analyst (VEDA) [9], that allows creating and managing the data input, running the model generator, and analysing results.

A consistent preliminary work performed a detailed characterisation of the scope and objectives of the analysis, which dealt with the following questions:

- What are the possible uses of the future model in the NEEDS as well as in other projects?

- What are the characteristics of the basic energy balances and other data sources to which the model will be calibrated?

Particular care was given to the design of the reference energy system common to all countries, which had to be sufficiently disaggregated to provide the required contributions to the set objectives but not so disaggregated that the required data would not be available, and that the resulting size of the linear programming (LP) problem would be difficult to handle by the optimizer and other software. Once the RES was agreed upon, the next step dealt with the design of spreadsheets and databases used to manage the data-input in a transparent and comprehensive way, as discussed below.

\subsection{The reference energy system (RES)}

From a methodological point of view, the first decision taken concerned the definition of the RES. As extensively described in the official deliverable [10], the following sectors were included: Residential, Commercial, Agriculture, Industry, Transportation, Electricity/Heat production, and Energy Supply. In particular, the structure of the RES was determined by identifying the demand categories, energy carriers, emissions, and materials to include.

In brief:

- Transportation includes road and rail for passengers and freight, navigation and aviation. In road transport, there are five demand categories for passenger travel (cars - short distance, cars -long distance, buses - urban, buses - intercity, two and three-wheelers/off road), and trucking. In rail transport, there are three demand categories (passengers - light trains (metros), passengers - heavy trains and rail freight). The aviation and navigation sectors are modelled using a single generic technology each and a single generic demand each that reproduces the energy consumption. 
- In Residential there are 11 end-uses (Space heating, Space Cooling, Water heating Cooking, Lighting, Refrigeration, Clothes washing, Clothes drying, Dish Washing, Other electric, Other energy), and the first three are differentiated by building categories (Single house - rural, Single house urban, Multi Apartment). Similarly, the RES structure of the Commercial sector has nine end-uses (Space heating, Space Cooling, Water heating, Cooking, Refrigeration, Lighting, Public Lighting, Other electric, Other Energy Uses), with the first three being differentiated by building categories (Small / Large). Agriculture is modelled as a single generic technology with a mix of fuels as input and an aggregated useful energy demand as output.

- Industry is divided in two different sets: energy intensive industries and other industries. For the energy intensive industries, a process-oriented RES was adopted, whereas for other industries a standard structure consisting in a mix of five main energy uses (Steam, Process heat, Machine drive, Electrochemical, Others processes) was adopted. In order to start moving in the direction of LCA/I and ExternE, different material demands of the industrial sector (as for example steel or limestone) were modelled separately.

- Electricity and Heat production: this sector regroups public power plants, auto production of electricity and CHP. In the RES, three types of electricity (High voltage, Medium voltage, and Low voltage) and two separated (not connected) grids for long distance (high temperature) and short distance (low temperature) heat are distinguished.

- Supply: Each primary resource (Crude Oil, Natural Gas, Hard coal, Lignite) is modelled by a supply curve with several cost steps. There are three categories of sources: located reserves (or producing pools), reserves growth (or enhanced recovery), and new discovery. In addition, five types of biomass are modelled: wood products, biogas, municipal waste, industrial waste-sludge, and bio fuels.

Energy carriers were chosen starting from those reported in the Eurostat [11] energy balances, and then aggregating some of them to adapt the list to the modelling objectives of the project. As concerns materials, it was decided to explicitly model only those whose production requires more energy or which are important for the production processes modelled (e.g. scrap steel). Other materials are implicitly modelled as part of the variable costs and their related emissions are accounted for in the process emissions. The air emissions modelled are Carbon Dioxide $\left(\mathrm{CO}_{2}\right)$, Carbon Monoxide $(\mathrm{CO})$, Methane $\left(\mathrm{CH}_{4}\right)$, Sulphur dioxide $\left(\mathrm{SO}_{2}\right)$, Nitrogen Oxides $\left(\mathrm{NO}_{\mathrm{x}}\right)$, Nitrous Oxide (NO), Particulate (PM 2.5 and PM 10), Volatile Organic Compounds (VOC), Sulphur hexafluorides $\left(\mathrm{SF}_{6}\right)$ and Fluoro Carbons. $\left(\mathrm{C}_{\mathrm{x}} \mathrm{F}_{\mathrm{y}}\right)$.

A RES example for the Iron and Steel industry, with the indication of the materials considered is shown in Figure 1.

\subsection{The base-year calibration}

The first step of the energy system analysis at country level dealt with the calibration of the model to selected data sources in the initial year. The Eurostat 
database was chosen as the main official common source of information. The section 'Energy and Environment' provides all the energy flows (production, transformation, consumption, trade) for the base-year (2000), as well as the net installed capacities for power plants, several technological parameters for nuclear plants (efficiency, availability, etc.) and import/export figures. As concerns transportation modes, the Eurostat data were integrated with those provided by DG TREN [12], whereas default inputs and outputs of energy intensive technologies (European average) come from the Western European Matter database of ECN [13]. In some cases, such as Italy, it has been necessary to correct major errors in the initial energy balances using national data sources.

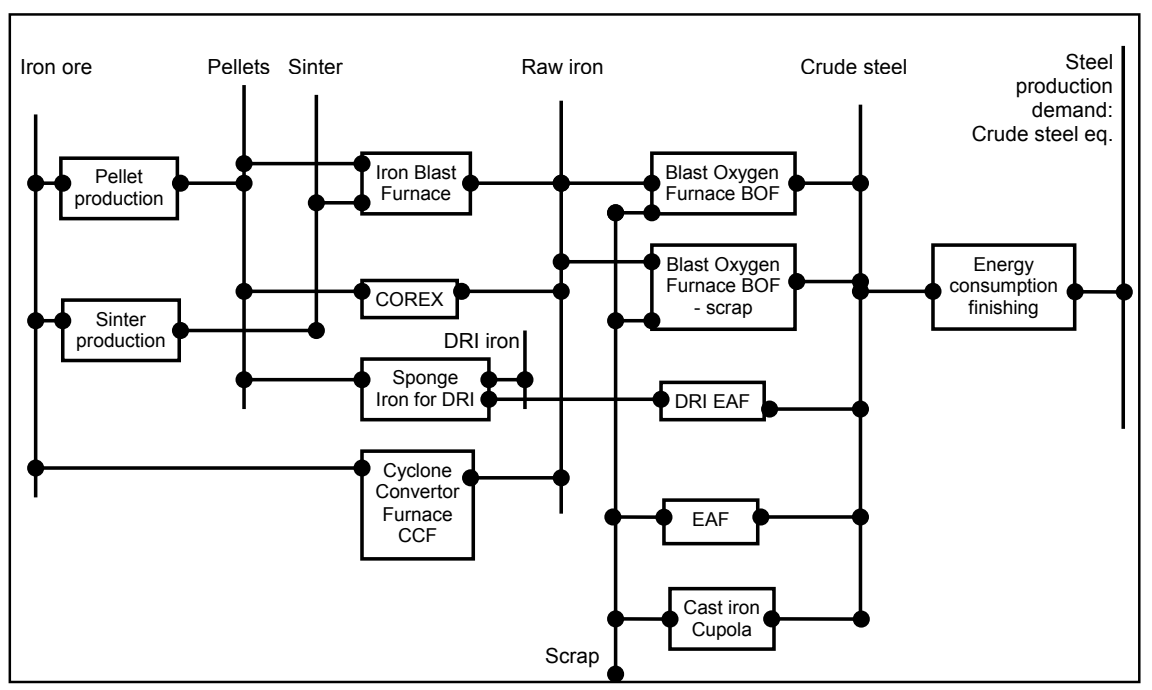

Figure 1: A RES example: the Iron and Steel industry (source ECN).

The characterisation of the analysed sectors was done by filling in five "templates" (RCA: Residential/Commercial/Agriculture, IND: Industry, TRA: Transport, ELC: Electricity/Heat production, and SUP: Energy Supply), which are elaborate Excel spreadsheets that lay down the basic structure of the country TIMES model and hold the data necessary to calibrate the energy flows of the base-year. Templates have direct links to primary data sources and are periodically updated. The templates collect the following information: base-year energy flows, existing technology stocks, with their technical/environmental characteristics, discount rate, and transmission efficiency. With these data consistent base year demands for energy services are computed.

As sketched in Figure 2, once the energy system has been characterised for the base year using the templates structure, these files are imported into VEDA-FE for running the TIMES model. The integration scheme for the whole process from data to model is given in the next figure.

Once the results of the base year are "stable", the investigation can be extended to the overall time horizon, as discussed in the following section. 


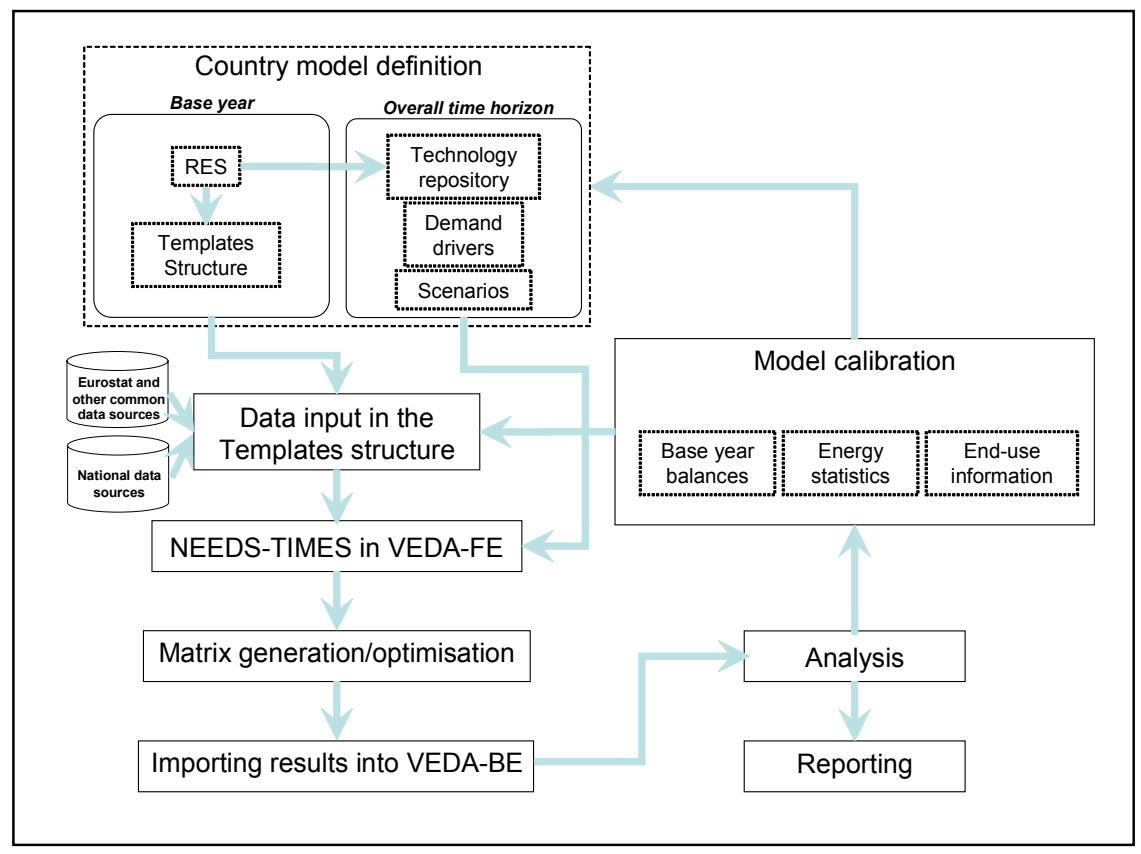

Figure 2: Schematic representation of the modelling process.

\subsection{The long-term analysis}

An analysis over a 50-year time horizon requires three additional inputs into VEDA-FE:

- Specification for existing and future technologies and fuels

- Demand drivers and elasticities

- Scenarios parameters

Technical and economic information on each existing and future technology in each sector (Residential, Commercial, Industry, Transportation, Supply and Power generation) over the entire time horizon is provided in Excel files. This information can also include data on life cycle emissions and external costs.

An example of the basic structure of the main data characterising a technology is shown in Table 1 and more specifically for power plants in table 2 .

The demand drivers allow generating the demand projections of energy services over the time horizon for the reference scenario (Business As usual BAU) as well as for the policy scenarios. In operational terms, the scenarios consist of sets of coherent assumptions about the future trajectories of demand drivers (population, GDP, sectors' outputs, households, etc.), leading to a coherent organization of the system under study [7]. For a TIMES model, once the drivers are determined and quantified, a set of energy service demands over the horizon is determined by specifying the elasticity of each demand to its respective driver, in each region, using the following general formula: 
Table 1: $\quad$ Typical structure of a technology definition.

\begin{tabular}{|l|l|l|l|l|l|}
\hline TECHNOLOGY NAME : & $\ldots$ & & & & \\
\hline \multicolumn{1}{|c|}{ Parameter } & \multicolumn{1}{c|}{ Unit } & Constant & $\mathbf{2 0 0 0}$ & [...] & $\mathbf{2 0 5 0}$ \\
\hline CAPACITY & $k W$ & $\ldots$
\end{tabular}

Demand's growth rate $=$ Driver's growth rate X Elasticity

In the NEEDS - TIMES model, for the reference scenario BAU [14], that follows business as usual trends, the general equilibrium model GEM-E3 Europe is used to produce the drivers' growth rates (GDP, sectors' growth, households, transport demand by households) in the various regions, based on assumptions on population growth, technical progress, and taking into account the recent developments in the oil and gas markets and the new DGTREN projection. It includes also the implementation of the Kyoto climate policy (with constant and moderate tax levels after 2012), and the adopted country decisions on nuclear energy [14].

Beside that, three policy scenarios of interest for EU stakeholders will be analysed at the Pan EU level [15], based on the following key issues:

- Long term Post Kyoto climate policy target (e.g. 550ppm or some other $\mathrm{CO} 2$-equivalent concentration).

- Enhancement of endogenous energy resources such as renewables and biofuels, and of energy conservation options through a combination of policies (renewables standards, energy efficiency standards, R\&D policy). 
- Local pollution policy targets for air quality, taking into account externalities (for which updated data will be provided by the other Research Streams).

Moreover, some scenarios variants will be considered regarding: oil price, the internalization or not of external cost in the first two scenarios (in all scenarios the cost or benefits in terms of external cost is always an output of the model), nuclear availability or not [15].

\section{Conclusions and further developments}

In the framework of the $6^{\text {th }}$ FP Integrated Project NEEDS, the use of TIMES model's equations, GAMS program and VEDA interface will allow research teams to implement and make available an unique modelling platform, accessible to other researchers. It will be characterised by a long-term time horizon, high technological detail (in energy supply and end-use sectors), open and updateable format without need to change the software. Moreover its built-in flexibility facilitates the integration of LCA and ExternE evaluation methodologies in the models.

The first steps of the work were directed to software development and implementation and to the development of the 29 country models that will constitute the basis of the Pan European model.

Next steps will deal with the finalisation of the Pan European model, testing its consistency in the reference scenario as well as on policy scenarios.

As main results of the scenario analysis, the energy system response is generated according to the different policy options and the exogenous scenario assumptions for the time horizon under analysis. Illustrative parameters of this response are the equilibrium quantities and prices of energy vectors (primary energy and secondary fuels), energy technologies, emissions (GHG and local air pollutants) and other burdens will be provided. These results will constitute new input data for both LCA and ExternE, to be used for iterative, convergent evaluations. This work will provide the foundation for including the end use technologies in the LCA and ExternE approach for balancing the environmental impacts for the whole energy system in future. Another important set of analysis will deal with the assessment of the possible market allocation of new technologies and with the analysis of different policies and measures to support national policies, providing a common basic framework for the definition of EU strategies.

\section{Acknowledgments}

This work was performed in the framework of the EU NEEDS project (Contract Number 502687), coordinated by the Institute of Studies for the Integration of Systems - ISIS, Rome (Italy) and supported by the Directorate General for Research of the European Commission in the context of the VI Framework Programme, Priority 6.1: Sustainable Energy Systems, Sub-priority 6.1.3.2.5: Socio-economic tools and concepts for energy strategy. 


\section{References}

[1] NEEDS "New Energy Externalities Developments for Sustainability", http://www.needs-project.org.

[2] ETSAP "The Energy Technology Systems Analysis Programme", http://www.etsap.org.

[3] Gielen, D., The Future Role of $\mathrm{CO} 2$ Capture and Storage - Results of the IEA-ETP Model, IEA/EET Working Paper, EET/2003/04, November 2003.

[4] Office of Integrated Analysis and Forecasting, Energy Information Administration, U.S. Department of Energy, Washington, DC, The System for Analysis of Global Energy markets (SAGE) model of the USEIA, DOE/EIA-M072 (2003)/1, August 2003. http://www.eia.doe.gov/ bookshelf/docs.html.

[5] Rafaj, P., Kypreos, S., Barreto, L., 2005: Flexible Carbon Mitigation Policies: Analysis with a Global Multi-regional MARKAL Model. In Haurie, A., Viguier, L., (Editors) Coupling Climate and Economic Dynamics, Kluwer Academic Publishers. Dordrecht, the Netherlands. ISBN 1-4020-3424-5.

[6] Haurie, A., Kanudia, A., Loulou, R., van Regemorter, D., Vaillancourt, K., The EFDA World Model. Final Report prepared for EFDA, ORDECSYS, HALOA/KANORS and KUL, 2004.

[7] Loulou, R., Remne, U., Kanudia, A., Lehtila, A. \& Goldstein, G., Documentation for the TIMES Model (Part I, II and III), Energy Technology Systems Analysis Programme (ETSAP), April 2005, http://www.etsap.org/tools.htm.

[8] GAMS “The General Algebraic Modeling System", www.gams.com.

[9] KanORS Consulting Inc., VEDA (VErsatile Data Analyst), http://www.kanors.com/software.htm.

[10] Loulou, R., Kanudia, A., Vaillancourt, K., Smekens, K., Tosato, G.C., Van Regenmorten, D., Blesl, M., Cosmi, C., Salvia, M. \& Schulz, T., Draft common structure of the national country models. Deliverable D1.4 of the EU Integrated Project NEEDS "New Energy Externalities Developments for Sustainability", 31 August 2005.

[11] Eurostat, Statistical Office of the European Communities, http://epp.eurostat.cec.eu.int.

[12] European Commission, Directorate General for Energy and Transport (DG TREN), Statistical pocketbook 2005 http://europe.eu.int/ comm/dgs/energy transport/figures/pocketbook/2004 en.htm.

[13] Kram, T., The MATTER project: integrated energy and materials systems engineering for GHG emission mitigation, BS: Report ECN-C--01-017, April 2001, http://www.ecn.nl/library/reports/2001/c01017.html.

[14] Kypreos, S., Van Regemorter, D., and Guel, T. Key Drivers for Energy Trends in EU; Specification of the Baseline and Policy Scenarios. NEEDS Internal working paper RS2a WP2.3, 12 January 2006. 
106 Environmental Economics and Investment Assessment

[15] Kypreos, S., and Van Regemorter, D. Scenarios to be generated with the TIMES model for NEEDS. NEEDS Internal working paper RS2a WP2.3, 27 February 2006. 